\title{
Impact of the number of blades of the geokhod cutting body on cutting forces
}

\author{
Vladimir Aksenov ${ }^{1,3}$, Vladimir Sadovets ${ }^{2,3 *}$,Elena Rezanova ${ }^{2}$, Dmitry Pashkov $^{2}$ \\ ${ }^{1}$ Institute of Coal SB RAS, Kemerovo 650065, Russia, Kemerovo, Leningradsky prospekt, 10 \\ ${ }^{2}$ T. F. Gorbachev Kuzbass State Technical University, Kemerovo, 650000, 28 Vesennaya street \\ ${ }^{3}$ Yurga Technological Institute TPU, Yurga 652050, 26 Leningradskaya street
}

\begin{abstract}
The article presents the power dependencies for determining the number of blades of the cutting body of geokhod for destruction of rocks of low hardness. The obtained dependences are based on the developed method of calculation of the blade cutting body of the geokhod. The presented dependences make it possible to choose the rational number of blades of the geokhod cutting body. The intensity of the development of underground space by the countries of the world community, including Russia, is increasing. In this connection, the tasks are to increase the rate of development and to reduce the cost of work.
\end{abstract}

\section{Introduction}

One of the areas of solving the problem mentioned above is application of geokhod technology, the basic element of which is the geokhod. At present, a prototype of geokhod is manufactured with the cutting body for destruction of rocks of medium hardness (Figure 1) [1-4].

Geokhods represent a new class of tunneling equipment. A basic feature of the geokhod is the screwing into the contour strata of the body which performs the function of the mobile support. At the same time, the force providing motion and balancing the reaction from the technological operations is formed not by friction forces at the media interface (soil-crawler mechanism) or repulsion from an artificially constructed support element (hydraulic jack-permanent support), but as a result of introducing the propulsion elements in the contour strata and the use of a normal reaction arising from the interaction of the elements of the geokhod with the rock mass [5-8].

When the geokhod is operating, the cutting body moves to the face in strict accordance with the pitch of the helical blade mounted on the outer surface of the head section (Figure 2). In this case, each point of the blade moves along the spiral trajectory.

\footnotetext{
"Corresponding author: vsadovec@yandex.ru
} 


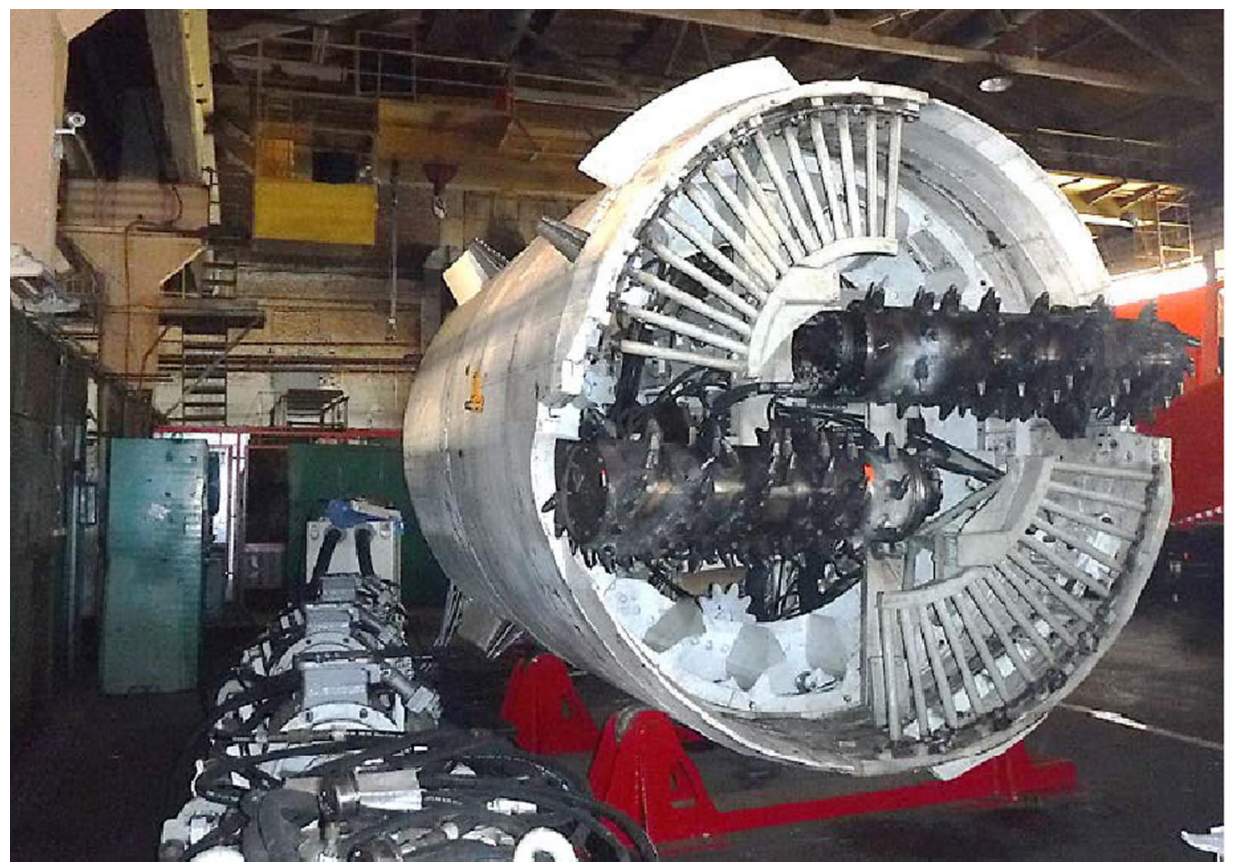

Fig. 1. Geokhod prototype with drum cutting body (CB)

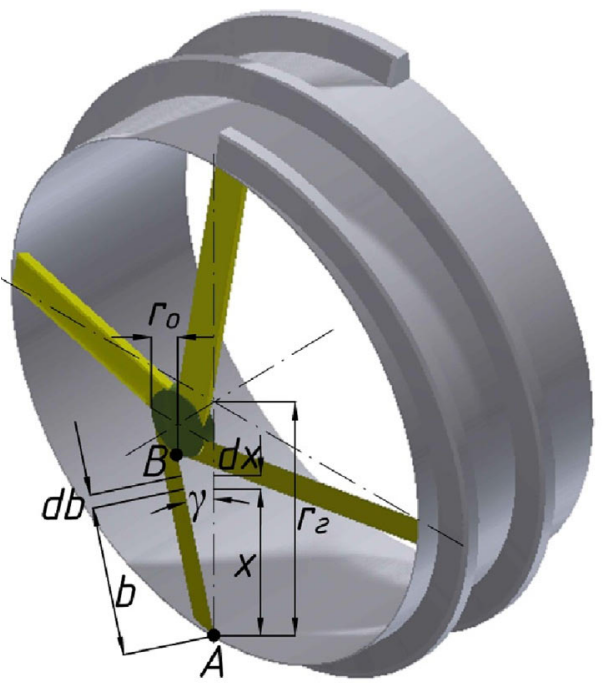

Fig. 2. Blade CB of geokhod

The blade points that are closer to the axis of rotation of the geokhod move to the face at a greater angle than the points on the periphery of the blade (Figure 3). Thus, with the helical motion of the blade cutting body to the face, the points of the blade trace out a helicoid (helical) surface. Consequently, the site of the face after the passage of the blade takes the form of a helical surface. The number of blades determines the number of mating areas with the helicoid surface on the face. Between the two mating helical surfaces, a ledge is constantly formed, which is destroyed by the CB blades as they are fed to the face [9-13]. 


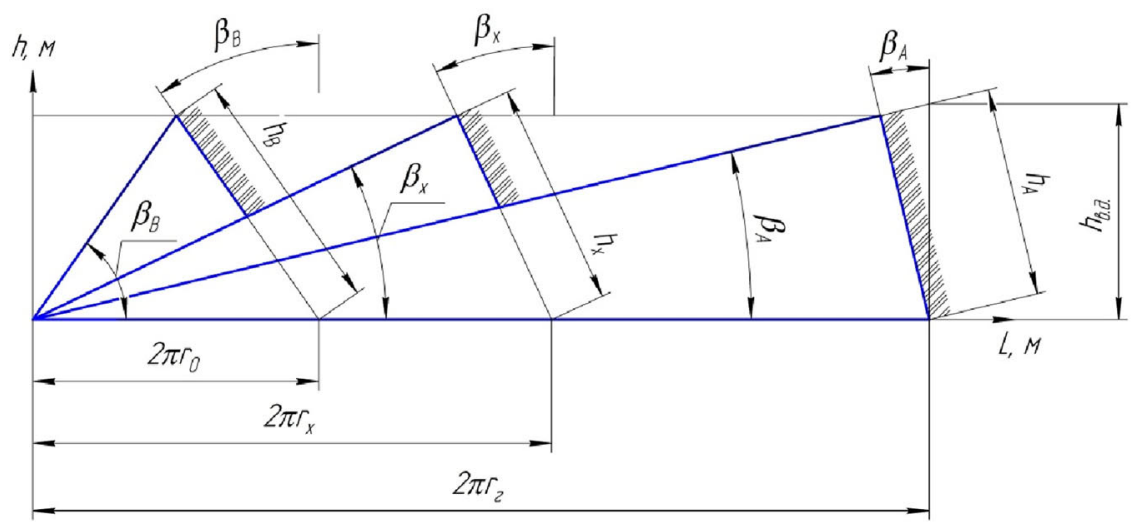

Fig. 3. Direction of movement of the points on CB blades depending on their location on the blade along the radius of geokhod

As follows from the determination of the power parameters of the geokhod blade cutting body presented in [2], cutting forces are affected by the radius of the geokhod, the lifting angle of the blade of the external propeller and the number of blades on the geokhod CB. The impact of the overall dimensions of the geokhod and the lifting angle of the helical blade of the external propeller on its power parameters are determined in work [14].

Based on the above, the task of the presented study is formulated as: determine the impact of cutting forces on the number of blades of the geokhod cutting body.

\section{The research techniques}

Based on the mining conditions of driving mine workings by the geokhod with the blade CB presented in Table 1 and the expressions used in works [15-17], the full projection of the soil cutting resistance force on the axis of rotation of the geokhod and the plane perpendicular to the axis of rotation were calculated as well as the total moment of resistance to cutting for a different number of sharp blades and the blades having the worn place or dulling.

Table 1. Mining and technical conditions for driving of a mine working by geokhod with a blade CB

\begin{tabular}{|l|c|c|c|}
\hline \multicolumn{1}{|c|}{ Description } & Designation & $\begin{array}{c}\text { Unit of } \\
\text { measure }\end{array}$ & Value \\
\hline Radius of geokhod & $r_{g}$ & $\mathrm{~m}$ & 1.6 \\
\hline Radius of generatrix [13] & $r_{o}$ & $\mathrm{~m}$ & 0.4 \\
\hline $\begin{array}{l}\text { Angle of inclination of CB blades to the axis of geokhod } \\
\text { rotation }\end{array}$ & $\alpha$ & degree & 90 \\
\hline Helical blade pitch & $H_{b}$ & $\mathrm{~m}$ & 0.6 \\
\hline Coefficient taking into account the cutting angle impact [14] & $\varphi$ & & 0.59 \\
\hline Specific cutting force in the front of slot at cutting angle 45 & $M_{\text {front }}$ & $\mathrm{N} / \mathrm{m}^{2}$ & 31000 \\
\hline Soil destruction force in side parts of the slot [14] & $M_{\text {side }}$ & $\mathrm{N} / \mathrm{m}^{2}$ & 9000 \\
\hline Specific cutting force by one of the side edges of blade [14] & $M_{\text {side.spec }}$ & $\mathrm{N} / \mathrm{m}^{2}$ & 740 \\
\hline $\begin{array}{l}\text { Angle of inclination of the radial blade to the plane } \\
\text { perpendicular to the axis of geokhod rotation }\end{array}$ & $\gamma$ & degree & 0 \\
\hline $\begin{array}{l}\text { Parameters characterizing material resistance to elastic- } \\
\text { plastic compression [14] }\end{array}$ & $\begin{array}{l}P_{O} \\
P_{u}\end{array}$ & $\begin{array}{c}\mathrm{N} / \mathrm{m} \\
\mathrm{N} / \mathrm{m}\end{array}$ & 11300 \\
\hline Cutting angle & $\delta$ & degree & 25 \\
\hline Friction angle [15] & $\varphi_{f r}$ & degree & 31.4 \\
\hline
\end{tabular}


Calculation of the power parameters of the blade $\mathrm{CB}$ of the geokhod with a radius of 1.6 with a pitch of the helical blade $\left(h_{\mathrm{b}}=0,6 \mathrm{~m}\right)$ was made in Microsoft Excel.

\section{Results}

Based on the calculations, graphs were plotted for the change in the projection of the total force of the rock cutting resistance on the axis of rotation of the geokhod $\left(P_{O}\right)$ as well as the projection on the plane perpendicular to the axis of rotation of the geokhod $\left(R_{C B}\right)$ and the moment of soil cutting resistance $\left(M_{C B}\right)$ for sharp knives with an increase in their number (Figure 4-a, b, c). On the axis of ordinates of the presented dependence, the values of the power parameters of the blade $\mathrm{CB}(\mathrm{H}$ and $\mathrm{Nm})$ are plotted, and along the axis of abscissae the change in the number of blades.
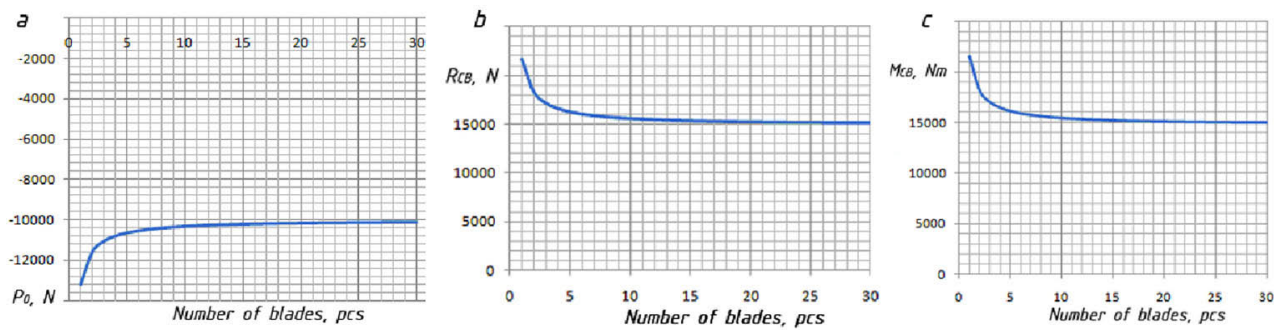

Fig. 4. a) dependence of the projection of the total resistance force of the rock to cutting on the axis of rotation of the geokhod $\left(P_{O}\right)$ for sharp blades on their number on the geokhod $\mathrm{CB}$; b) dependence of the projection on the plane perpendicular to the axis of geokhod rotation $\left(R_{C B}\right)$ for sharp blades on their number on the geokhod CB; c) dependence of the moment of soil resistance to cutting $\left(M_{C B}\right)$ for sharp blades on their number on the geokhod CB

It can be seen on the graphs that the projection of the total resistance of rock to cutting on the axis of rotation of the geokhod $\left(P_{O}\right)$ increases with the increase of sharp blades, and the projection on the plane perpendicular to the axis of rotation of the geokhod $\left(R_{C B}\right)$ and the moment of soil resistance to cutting $\left(M_{C B}\right)$ for sharp knives decreases with the increase of the blades quantity.

Figure 5-a, b, c shows graphs of the change in the projection of the total resistance of rock to cutting on the axis of rotation of the geokhod $\left(P_{O}\right)$ as well as the projection on the plane perpendicular to the axis of rotation of the geokhod $\left(R_{C B}\right)$ and the moment of soil resistance to cutting $\left(M_{C B}\right)$ for dull knives with the increase of their quantity.

On the axis of ordinates, the values of the power parameters of the blade $\mathrm{CB}(\mathrm{N}$ and $\mathrm{Nm}$ ) are plotted, and along the axis of abscissae - the change in the number of blades.
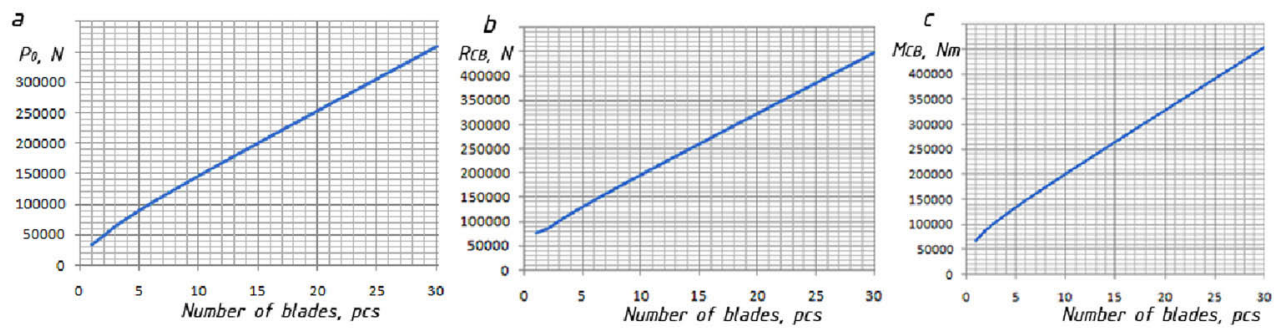

Fig. 5. a) dependence of the projection of the total resistance force of the rock to cutting on the axis of rotation of the geokhod $\left(P_{O}\right)$ for dull blades on their number on the geokhod $\mathrm{CB}$; b) dependence of the projection on the plane perpendicular to the axis of geokhod rotation $\left(R_{C B}\right)$ for dull blades on their number on the geokhod $\mathrm{CB}$; c) dependence of the moment of soil resistance to cutting $\left(M_{C B}\right)$ for dull blades on their number on the geokhod CB 
During operation, the cutting edge of the blade wears out and a blunt area is formed. This area affects the cutting forces negatively. This effect is observed on the graphs shown in Figure 5. Based on the graphs, it is seen that with increase in the number of blunted blades, the cutting forces increase.

\section{Conclusion}

On the basis of the graphs shown in Figures 4-5, it can be concluded that the rational number of blades geokhod CB is in the range from 2 to 12 , as the cutting forces increase with increasing number of blunt blades, and with increasing number of sharp knives, the cutting forces decrease, But after 12 the forces do not practically decrease and further become constant. In this regard, it is not rational to use more than 12 blades due to the fact that the cutting forces are spent more on overcoming the resistance of the blunting area, rather than on cutting itself.

\section{References}

1. A.V. Walter, V.V. Aksenov, Applied Mechanics and Materials, 770, 439 (2015)

2. V.Y. Sadovets, V.Y. Beglyakov, V.V. Aksenov, IOP Conference Series: Materials Science and Engineering, 91, 012085 (2015)

3. A.A. Kazantsev, O.A. Mikenina, A.F. Revuzhenko, IOP Conference Series: Materials Science and Engineering, 91, 012090 (2015)

4. A.B. Efremenkov, V.Y.Timofeev, IEEE (2012)

5. V.Y. Begljakov, V.Y. Timofeev, M.V. Dokhnenko, Applied Mechanics and Materials, 682, 282 (2014)

6. R.V.Chernukhin, A.A.Dronov, M.Y.Blashchuk, IOP Conference Series: Materials Science and Engineering, 91, 012086 (2015)

7. V.Y. Sadovets, V.Y. Beglyakov, A.B. Efremenkov, Applied Mechanics and Materials, 770, 384 (2015)

8. V.A. Petrova, A.A. Bakanov, A.V. Walter, Applied Mechanics and Materials, 682, 431 (2014)

9. S.A. Zhironkin, A.A. Khoreshok, M.A. Tyulenev, G.A. Barysheva, M.C. Hellmer, IOP Conf. Ser.: Mater. Sci. Eng., 142, 012127 (2016).

10. D. Nesteruk, M. Momot, IEEE (2012)

11. Yu.V. Lesin, S.Yu. Luk'yanova, M.A. Tyulenev, J. Min. Sci., 46, 78 (2010)

12. M. Tyulenev, S. Zhironkin, K. Kolotov, E. Garina, Pollution Research, 35, 221 (2016)

13. A.A. Kazantsev, V.P. Kosykh, A.F. Revuzhenko, IOP Conference Series: Materials Science and Engineering, 91, 012089 (2015)

14. A.A. Kazantsev, O.A. Mikenina, A.F. Revuzhenko, IOP Conference Series: Materials Science and Engineering, 91, 012090 (2015)

15. M. Tyulenev, E. Garina, A. Khoreshok, O. Litvin, Y. Litvin, E. Maliukhina, IOP Conf. Ser.: Earth Environ. Sci., 50, 012035 (2017)

16. M.Y. Blaschuk, A.A. Dronov, S.S. Ganovichev, IOP Conf. Ser. Mater. Sci. Eng., 142, 012128 (2016)

17. A.V. Koperchuk, A.V. Murin, V.V. Filonov, IOP Conf. Ser. Mater. Sci. Eng., 127, 012040 (2016) 